\title{
CARTOGRAFIA COMO PROCEDIMENTO METODOLÓGICO NO GRUPO DE ESTUDOS CERÂMICOS DO NUPEART PRO...MOVE
}

Aionara Preis Gabriel 
Este trabalho tem como proposta apresentar algumas reflexões acerca da cartografia como método de pesquisa desenvolvido junto ao Grupo de Estudos Cerâmicos, formado por estudantes da graduação em Artes Visuais e participantes do programa de extensão universitária NUPEART Pro... Move da Universidade do Estado de Santa Catarina, que procura unir o ensino teórico e prático da cerâmica por meio de encontros investigativos.

Extraída da noção de rizoma, termo emprestado da botânica por Gilles Deleuze e Félix Guattari, a cartografia é uma prática singular com ênfase no processo e na horizontalidade de relações, que legitima a construção coletiva de conhecimento. Com base em alguns procedimentos e propostas desenvolvidas durante os encontros, serão expostas algumas considerações sobre o método cartográfico e as ações produzidas pelo grupo durante o biênio de 2016 e 2017.

Palavras-Chave: Rizoma; Cartografia; Metodologia de pesquisa.

\section{INTRODUÇÃO}

Doi durante a participação como bolsista do curso de Modelagem -1 e Preparação de Massas Cerâmicas para Queimas Alternativas do L programa de extensão universitária NUPEART ${ }^{1}$ Pro...Move da Universidade do Estado de Santa Catarina, estando à frente da coordenação do Grupo de Estudos Cerâmicos, que algumas questões de ensino e aprendizado começaram a surgir. As indagações mais pertinentes foram: quais as maneiras que efetivam o processo de pesquisa e como estabelecer objetivos que sejam comuns a todos? Com estas indagações, serão elucidados neste texto os desdobramentos da cartografia como metodologia de pesquisa no Grupo de Estudos Cerâmicos com as ações desenvolvidas durante os anos de 2016 e 2017.

A utilização do termo cartografia, emprestada do campo de conhecimento da geografia e que busca através de mapas representar graficamente a superfície terrestre, é utilizada por Deleuze e Guattari na Introdução do livro "Mil platôs" (2011) como um dos princípios do rizoma.

É possível esclarecer o conceito de rizoma utilizado na filosofia visitando o campo da botânica para entender o empréstimo deste termo. O rizoma é a estrutura terrestre ou subterrestre de algumas plantas que conseguem se conectar de um ponto a outro qualquer, permitindo a reprodução, o alastramento horizontal e a transferência de nutrientes de

\footnotetext{
1 Núcleo Pedagógico de Educação e Arte - desenvolve ações articulando ensino, pesquisa e extensão na arte, desde o ano 2000 . É formado por professores, alunos, egressos e demais grupos interessados, buscando dinamizar os conhecimentos produzidos no CEART - Centro de Artes da UDESC, à comunidade externa. Dentro deste núcleo encontra-se o Projeto NUPEART Pro...Move do curso de Artes Visuais, que tem como coordenadora a Prf.a Ms.a Rosana Tagliari Bortolin, que vem desenvolvendo diversas ações envolvendo arte e cerâmica na cidade de Florianópolis/SC.
} 
um broto a outro. Deleuze e Guattari utilizam este termo para ilustrar filosoficamente os processos de construção do conhecimento humano, representando o pensamento que se propaga em vastidão, confrontando com a ideia da árvore como representação cartesiana do saber. A ideia desta grande árvore na área da educação, com raízes, troncos e galhos, fragmenta as áreas dos saberes e dificulta o processo de aprendizagem, bloqueando o desenvolvimento de uma percepção holista da realidade. A crítica a este sistema mecânico do conhecimento na educação se dá pela inércia que o modelo representa, onde as áreas do conhecimento estão alocadas em galhos e estes por sua vez, só se comunicam com o tronco e nunca entre si (GALLO, 2008, p. 73).

Para clarificar o conceito de rizoma criado por Deleuze e Guattari (2011), serão enumeradas as seis noções básicas desenvolvidas pelos filósofos:

$1^{\circ}$ e $2^{\circ}$ - Princípios de conexão e heterogeneidade: qualquer ponto de um rizoma pode ser conectado a qualquer outro, sem findar, produzindo novas características.

$3^{\circ}$ - Princípio de multiplicidade: as possibilidades de conexões e heterogeneidade constituem a multiplicidade e é esta condição que redimensiona as relações para outras naturezas.

$4^{\circ}$ - Princípio de ruptura a-significante: sem hierarquias, o rompimento do rizoma pode ser feito em qualquer lugar, reorganizando e resignificando todo o conjunto.

$5^{\circ}$ e $6^{\circ}$ - Princípio de cartografia e de decalcomania: o rizoma é mapa que não pode ser justificado, comparado com nenhum outro. Ele pode ser cartografado pelas transformações da realidade. $\mathrm{O}$ decalque neste caso, codifica, organiza e estruturaliza o rizoma, reproduzindo nele mesmo apenas os impasses e pontos de organização.

As características que aproximam o rizoma botânico ao conceito de rizoma apresentadas pelos filósofos são como um olhar estratégico, que provoca novos princípios, diferente dos tradicionais que são unitários, verticais e disciplinares. O rizoma se alastra horizontalmente, é acêntrico, múltiplo, extenso, não tem começo nem fim e, por conseguinte, não possui hierarquias.

A empregabilidade destes e outros conceitos oriundos de diferentes áreas tornam-se interessante, segundo GALLO (2008), quando permitem que o filósofo possa (re)criar o mundo à sua maneira, estimulando os pensamentos com novos dispositivos e possibilitando conexões inusitadas entre os discursos científicos. Portanto, o conceito não pode ser uma definição exata, pois seria matar a própria potência criativa do conceito. 


\begin{abstract}
Ora, para nossos filósofos, o conceito não é uma representação, muito menos uma representação universal. Podemos definir o conceito, na visão dos filósofos franceses, como sendo uma aventura do pensamento que institui um acontecimento, vários acontecimentos, que permita um ponto de visada sobre o mundo, sobre o vivido. Poderíamos, aqui, lembrar a célebre afirmação de Merleau-Ponty: "a verdadeira filosofia consiste em reaprender ver o mundo"; parece ser disso que falam Deleuze e Guattari quando exprimem a ação do conceito: um reaprendizado do vivido, uma ressignificação do mundo. É por isso que o conceito é exclusivamente filosófico. A Ciência, por exemplo, não cria conceitos; ela opera com proposições ou funções, que partem necessariamente do vivido para exprimi-lo. (GALLO, 2008, p. 38)
\end{abstract}

Para isto, é necessário saber seu significado, suas condições e possibilidades de produção. Deste modo os conceitos de Deleuze e Guattari podem ser analisados em sua origem terminológica, contextual e posto em prática em diversos fenômenos contemporâneos, como a educação e os modos não lineares de ensino e aprendizagem. Estas mudanças conceituais no âmbito educacional é que legitimam outras formas autênticas de ensino e pesquisa.

No livro Pistas do método da cartografia: pesquisa-intervenção e produção de subjetividade (2015), Passos, Kastup e Escóssia apropriaram-se dos princípios do rizoma a fim de responder inquietações relativas à metodologia de pesquisa. A cartografia surge então como um desses princípios que representa o acompanhamento de percursos, a produção e conexão rizomática do pesquisar, propondo a reversão metodológica do metá-hódos: ou seja, o caminhar (hódos) predeterminado no início pelas metas, deve ser trocado por hódos-metá: que sugere que as metas devem surgir durante o caminhar.

Em vez de regras para serem aplicadas, propusemos a ideia de pistas. Apresentamos pistas para nos guiar no trabalho da pesquisa, sabendo que para acompanhar processos não podemos ter predeterminada de antemão a totalidade dos procedimentos metodológicos. As pistas que guiam o cartógrafo são como referências que concorrem para a manutenção de uma atitude de abertura ao que vai se produzindo e de calibragem do caminhar no próprio percurso da pesquisa - o hódosmetá da pesquisa. (PASSOS, KASTRUP, ESCÓSSIA, 2015, p. 13).

Embora existam muitas cartografias possíveis, bem como variados campos a serem cartografados, é importante ressaltar que cada contexto possui características próprias que possibilitam desenvolver necessidades e estratégias metodológicas diferenciadas, evidenciando que método e objeto possuem singularidades e que não existem regras ou estratégias preestabelecidas para serem percorridas. Desta forma, os participantes 
do Grupo de Estudos Cerâmicos desenvolveram ao longo dos encontros, diferentes atividades e métodos de pesquisa de acordo com seu percurso e suas expectativas.

A articulação da cartografia como metodologia e dos demais princípios do rizoma ajudará a entender como se efetivou o processo coletivo de investigação no Grupo de Estudos Cerâmicos e de que maneira essas pesquisas e experiências reverberaram.

\section{Princí́tios Equivalentes}

A cerâmica é uma linguagem que permite infinitas combinações, $\triangle$ iniciando com os diferentes tipos de argilas, queimas, revestimentos $\mathcal{L}$ e as diferentes maneiras de trabalhar e combinar estes materiais. comum ouvir dizer que o ceramista, durante o processo do fazer cerâmico em seu ateliê, não possui domínio total de seu trabalho, pois, as condições de secagem, a umidade do ar, a transformação da matéria pela ação do fogo e todos os demais fatores que se ligam a esta prática, podem interferir de maneira positiva ou negativa em um trabalho. Por atuar em conjunto com as forças dos quatros elementos da natureza: água, terra, ar e fogo, requer que o ceramista conheça os materiais e suas especificidades para evitar prejuízos.

Os conhecimentos técnicos, científicos, ferramentas específicas, local adequado de trabalho e liberdade de criação, são características indispensáveis, porém não obrigatórias, para o bom resultado do trabalho. Foi esta pluralidade da cerâmica que despertou o interesse de alunos da graduação em Artes Visuais e participantes do curso de extensão universitária Modelagem e Preparação de Massas Cerâmicas para Queimas Alternativas da Universidade do Estado de Santa Catarina - UDESC, a se encontrarem semanalmente para conversar, pesquisar, experimentar, analisar resultados e compartilhar experiências sobre esta grande área. A possibilidade de conexão com outros conteúdos, como geografia, geologia, química, física, história e arte, comprovam que a cerâmica como área do saber é composta parcialmente por várias outras, formando uma cartografia construída a partir dessas conexões.

Os encontros tinham duração de uma hora e meia e aconteciam nas quartas feiras, antes do curso de extensão. $\mathrm{O}$ objetivo era pesquisar em diferentes fontes, as mais variadas questões técnicas e teóricas que envolvem a cerâmica e a partir destas pesquisas realizar experimentos, deixando a produção plástica para ser desenvolvida durante as horas do curso. 
Entre os dois anos de encontro (2016 e 2017), o Grupo de Estudos Cerâmicos teve em seu total 15 participantes, com distintas idades e formações, como: eletricista, padeiro, geólogo, professor de arte, professor de física, ceramista, agrônomo, estudantes de artes visuais, dentista, engenheiro civil e socióloga. A heterogeneidade de idades, formações e experiências contribuíram de maneira positiva, tonificando a pesquisa e as relações constituídas durante os encontros.

As possibilidades de combinações no rizoma não são determinadas pelos sujeitos ou objetos, mas sim pelas determinações e dimensões das conexões, que, ao crescerem, transmutam a sua natureza (DELEUZE; GUATTARI, 2011). Desta forma, a multiplicidade de conexões durante os encontros ocorreu quase que de modo natural, com os participantes trazendo contribuições de suas várias áreas de conhecimento e interesse. Assim, todos os assuntos que se mostraram pertinentes, eram estudados e investigados com empenho.

Outra característica rizomática são as múltiplas entradas e saídas. Por não possuir início, meio e fim, o rizoma pode ser iniciado, rompido ou retomado em qualquer parte, pois todas as linhas que se conectam carregam informações do conjunto. Neste sistema não hierárquico e a-significante, novas conexões podem ser realizadas independentes do lugar que se inicia a pesquisa. Este mesmo entendimento também se aplica na cerâmica quando um conteúdo ou etapa é interdependente das demais, carregando informações do todo. Frequentemente um assunto trazia consigo informações sobre outras etapas ou exigia que a pesquisa fosse ampliada. Por exemplo, ao estudar sobre queimas cerâmicas, foi preciso ter noções das características das matérias primas, secagem das peças, controle de queima e sinterização ${ }^{2}$ da argila.

Em um grupo de estudos, os objetivos e interesses devem ser coletivos, desta forma, não existe ato solitário. Segundo Gallo (2008, p. 69), "Não há sujeitos, não há objetos, não há ações centradas em um ou outro; há projetos, acontecimentos, individuações sem sujeito. Todo projeto é coletivo. Todo valor é coletivo. Todo fracasso também." Como a formação do grupo deuse para investigar conteúdos desconhecidos, o fracasso ou aquilo que não se pode controlar no processo da queima cerâmica, também foi uma forma de aprendizado.

Durante as pesquisas sobre a primeira queima da cerâmica, comumente chamada de queima de biscoito, em razão de que a água física contida na peça é eliminada com $100^{\circ} \mathrm{C}$ e a água química é eliminada até os $600^{\circ} \mathrm{C}$ (CANOTILHO, 2003), foi realizada a experiência da queima no 
forno a lenha da UDESC onde ocorreu o seguinte fato. O forno a lenha exige monitoramento, vigia, zelo, pois é preciso alimentá-lo com lenha constantemente, sem subir a temperatura rapidamente e nem deixá-lo esfriar. Para controlar a temperatura utiliza-se o termopar ou monitora-se pela quantidade de combustível colocado com relação ao tempo e também pela cor do fogo. Somente após os $600^{\circ} \mathrm{C}$ é que os materiais sinterizam conferindo resistência física à peça (CANOTILHO, 2003). Mesmo a queima tendo 12 horas de duração, foi possível prever que a temperatura ideal não seria atingida, isso porque a maior parte da lenha disponível não possuía alto coeficiente de combustão, dificultando a elevação da temperatura. Ao abrir o forno, constatou-se que o resultado não foi satisfatório, pela cor da cerâmica e pelo som que ela emite quando algum objeto rígido bate sobre sua superfície. É um trabalho cansativo, de exclusividade, impossível de se ausentar, mas quando realizado em conjunto transforma-se em uma festividade. Mesmo que a queima não teve êxito total, o processo de realizar uma prática torna-se eficiente enquanto parte do desenvolvimento da pesquisa.

A palavra processo é diferenciada em dois sentidos por Barros e Kastrup (2015): como processamento e processualidade. Processamento está ligado à teoria da informação, seguindo modelos computacionais. No entanto, se processo for entendido como processualidade, está-se no coração da cartografia.

Diferentemente, o caminho da pesquisa cartográfica é constituído de passos que se sucedem sem se separar. Como o próprio ato de caminhar, onde um passo segue o outro num movimento contínuo, cada momento da pesquisa traz consigo o anterior e se prolonga nos momentos seguintes. (BARROS;KASTRUP, 2015, p. 59).

Desta forma, a processualidade tão presente no fazer cerâmico, como também em outros fazeres artísticos, se revela como um estado de constante pesquisa, experimentação e criação.

Considerando que existem diferentes formas de aprender, só é possível saber o método mais eficiente experimentando. Durante os encontros do Grupo de Estudos Cerâmicos, foram realizados diferentes procedimentos metodológicos que contribuíram com a pesquisa teórica e prática, uma vez que é com a somatória das maneiras de aprendizado que é possível relacionar, (re)ordenar, (re)configurar e (re)significar os conteúdos. Embora um caminho cartografado não possa ser reproduzido devido à inexistência de regras, definições e certezas do acaso, o decalque neste caso, pode estruturar os principais pontos de impasse da pesquisa.

Usualmente os encontros se davam da seguinte maneira: o assunto eleito era pesquisado por todos e discutido no encontro seguinte; se necessário realizava-se uma prática e permanecia-se no assunto até que fosse necessário. 
No entanto, ao pesquisar sobre esmaltes cerâmicos, foi preciso recorrer a outras formas de aprendizado, como palestra e workshop. As dúvidas surgiram logo no início da pesquisa com a diferença das nomenclaturas entre esmaltes ou vidrados, vidrados crus e fritas. No livro Manual de Esmaltes Cerámicos, Tomo 1 (1988), Chiti esclarece que todos são compostos por matérias-primas vitrificantes, fundentes, estabilizantes e podem ser alterados por opacificantes e colorantes, variando a quantidade e tratamento destes materiais. A sílica, principal matéria-prima do vidro, precisa de altas temperaturas para fundir, aproximadamente entre $1.700^{\circ} \mathrm{C}$ e $1.800^{\circ} \mathrm{C}$. Para baixar a temperatura da sílica, usam-se os fundentes, matérias-primas que contém suas características e pontos de fusão específicos. Os estabilizantes são responsáveis pela viscosidade e por manterem o vidrado fundido sobre a peça (CHITI, 1988).

Os desafios encontrados diante de tantas variantes e especificidades químicas foram reconhecidos por todos, sendo necessário recorrer a outros meios de apreensão. Sendo assim, foi solicitado auxílio para as pesquisas do grupo à ceramista e professora aposentada do curso de química da Universidade Federal de Santa Catarina - UFSC, Dr. ${ }^{a}$ Marina Uieara, que tem se dedicado a cerâmica, especificamente a formulação de esmaltes. Atendendo as necessidades do grupo e oportunizando demais interessados, foi realizada uma palestra sobre esmaltes cerâmicos e um workshop de Formulação de Esmaltes Cerâmicos, ambos aconteceram no ateliê de cerâmica da UDESC.

Figura 1 - Palestra sobre esmaltes cerâmicos realizada no dia 07 de junho de 2017.

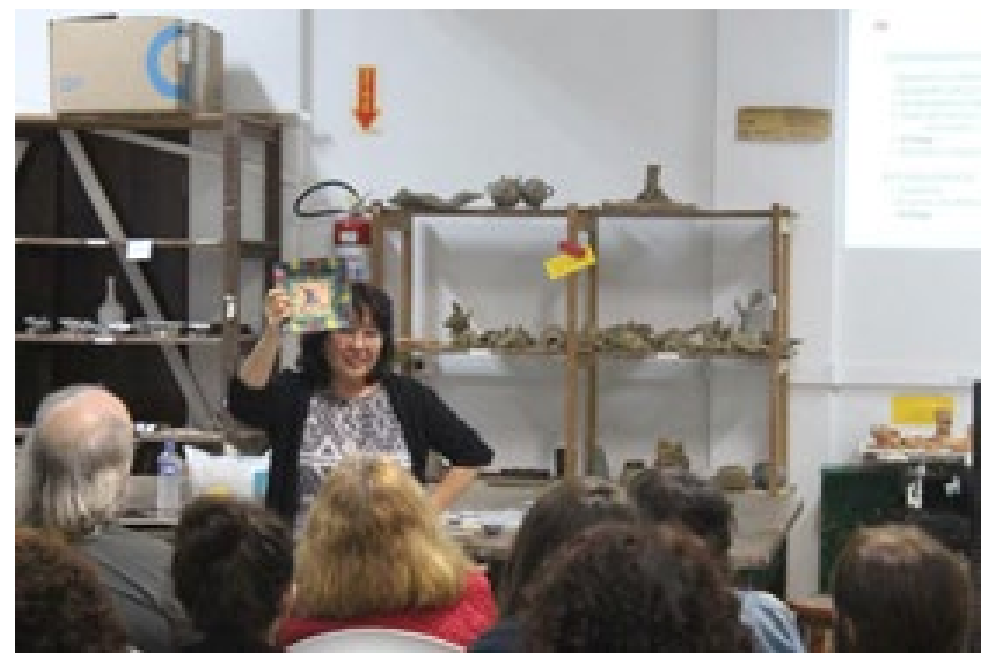

Fonte: Acervo pessoal. 
Oworkshop de Formulações de Esmaltes Cerâmicos além de complementar com a palestra serviu como incentivo no desenvolvimento das pesquisas, pois a possibilidade de elaborar os próprios esmaltes, reconhecer as características de cada matéria-prima e se deslumbrar com a exclusividade das cores, podem ser consequências gratificantes ao ceramista ou aprendiz desta prática.

Figura 2 - Workshop de Formulação de Esmaltes cerâmicos realizado no dia 13 de junho de 2017.
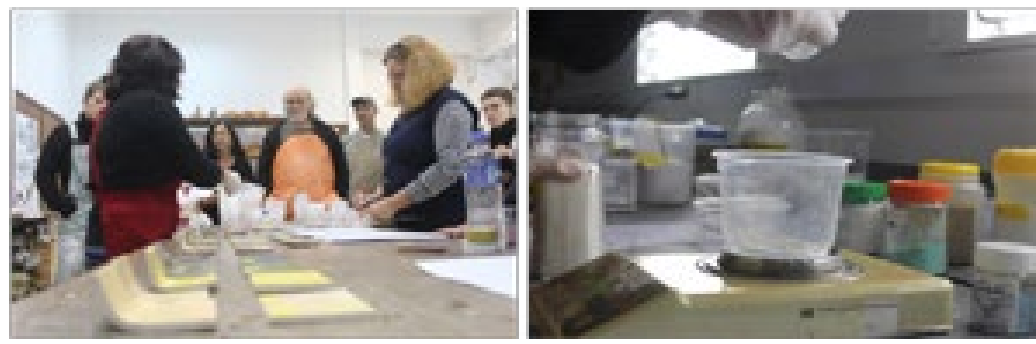

Fonte: Acervo pessoal.

Ainda que os participantes realizassem as mesmas formulações e utilizassem as mesmas matérias-primas, os resultados dos esmaltes tiveram diferenciações devido à localidade da placa dentro do forno, da pincelada e da argila utilizada na placa por cada participante do grupo, formando uma composição muito singular. De nada adianta colecionar ou aplicar mecanicamente fórmulas prontas de esmaltes "sobre cualquier tipo de pasta sin ajuste prévio, salvo por casualidad. Y es mejor que ello así sea, pues, de no serlo, el nuestro dejaría de ser um arte para convertirse em mecanismo ciego." (CHITI, 1988, p. 06).

Figura 3 - Resultado dos esmaltes.

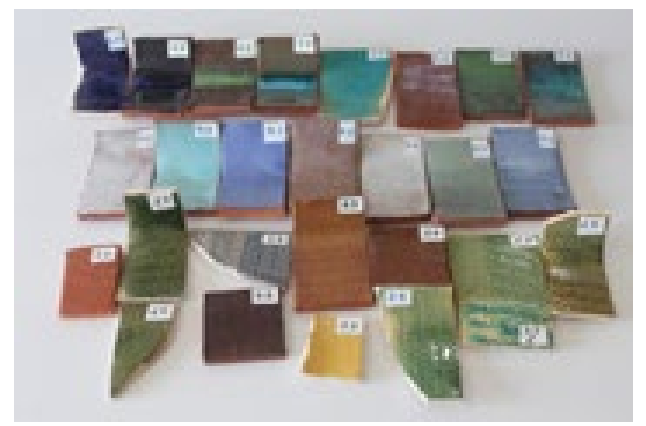

Fonte: Acervo pessoal.

Ter conhecimento dos materiais e suas respectivas funções possibilita ao ceramista tornar-se independente dos produtos prontos desenvolvendo suas próprias fórmulas, ampliando a possibilidade de criação para a composição de cores, texturas e formas. Esta constante investigação, exige que o ceramista em seu 
ateliê adote postura de artista e cientista ao mesmo tempo, sendo que ambas estão interligadas e são responsáveis pelo processo de criação.

Nessa composição, cartografar é acompanhar processo, é seguir o movimento e constituir-se nele. São nos encontros ocorridos com o grupo e na relação entre sujeito e objeto que os métodos e procedimentos a serem desenvolvidos são sinalizados. Para perceber estes sinais, Kastrup (2015), definiu em quatro variedades o funcionamento atencional do trabalho do cartógrafo: rastreio, toque, pouso e reconhecimento. $\mathrm{O}$ rastreio é a identificação da área e de metas que se deslocam. Em suas palavras:

Rastrear é também acompanhar mudanças de posição, de velocidade, de aceleração, de ritmo. O rastreio não se identifica a uma busca de informação. A atenção do cartógrafo é, em princípio, aberta e sem foco, e a concentração se explica por uma sintonia fina com o problema. (KASTRUP, 2015, p. 40).

O tato é uma qualidade sensorial que está presente em todo o corpo e tem a capacidade de receber todas as percepções referentes à zona de contato. Ao invés da percepção tátil passiva, utiliza-se a percepção háptica que abrange outras sensações relacionadas ao toque, formando um bloco tátil-sinestésico. Deleuze utiliza o deslocamento de uma ameba para exemplificar o movimento da percepção háptica. "O movimento da ameba é regido por sensações diretas, por ações de forças invisíveis como pressão, estiramento, dilatação e contração. Não é o movimento que explica a sensação, mas, ao contrário, é a elasticidade da sensação que explica o movimento." (Deleuze, 1981, apud KASTRUP, 2015, p. 42).

O pouso indica que a percepção sensorial está concentrada em um ponto, formando-se um zoom com diferentes níveis de atenção, que reconfigura todo o território. A quarta característica da atenção é o reconhecimento que se manifesta quando a atenção é atraída por algo, obrigando uma pausa no processo. Em uma pesquisa construtiva, este reconhecimento atento se apropria de objetos e situações inesperadas para produzir conhecimento.

Ao adentrar em pesquisas sobre cerâmica é preciso estar disposto a transitar por territórios mapeados como se fosse à primeira vez. Esta área é caracterizada pelas multiplicidades e incertezas, exigindo que o ceramista aprenda a conviver com esta instabilidade e que a partir dela possa tirar possibilidades criativas. Este estado de incessante pesquisa se assemelha ao que Kastrup (2015) reconhece como a conduta do cartógrafo:

Defender que toda pesquisa é intervenção exige do cartógrafo um mergulho no plano da experiência, lá onde conhecer e fazer se tornam inseparáveis, impedindo qualquer pretensão à neutralidade ou mesmo suposição de um sujeito e de um objeto cognoscentes prévios à relação que os liga. (KASTRUP, 2015, p. 30).

Assim como na metodologia cartográfica, na qual não é possível caminhar duas vezes sobre o mesmo campo de pesquisa, o ceramista também em seu processo de pesquisa encontra novos procedimentos de trabalho. Nunca o cartógrafo será 
apenas observador, ele estará presente facilitando os fluxos de novas conexões. Nunca o ceramista em seu ateliê terá supremo domínio dos materiais e procedimentos, ele estará sempre imerso no plano da experiência, (re)constituindo-se no caminho.

satisfação de estudar e pesquisar em grupo se dá pela união dos objetivos
pessoais serem comuns a todos e pela heterogeneidade do grupo. Estas
características quesãoimensuráveis evariáveis proporcionamamultiplicidade de resultados e conexões, que se transformam constantemente em novas cartografias.

A aprendizagem dentro da perspectiva rizomática é singular, horizontal, multicafetada, maleável, resignificante e possibilita um acesso diferenciado às áreas do saber. Dentro deste contexto, a educação poderia se tornar um processo muito mais condizente com as exigências da contemporaneidade (GALLO, 2008).

Quando se pretende cartografar umaárea do conhecimento,é preciso transitar por diferentes saberes com estratégias flexíveis, a fim de identificar as necessidades de cada situação. $\mathrm{O}$ cartógrafo deve estar em estado absoluto durante a produção de conhecimento, analisando as relações entre sujeito e objeto para a partir delas, explorar os desejos e as potencialidades.

O grupo de Estudos Cerâmicos surgiu para que algumas perguntas fossem respondidas, porém chegou o momento em que haviam mais perguntas que respostas, mais dúvidas que certezas. Supostamente seria este o sentimento de desejo mencionado por Deleuze e Guattari (2011, p. 32):

Quando um rizoma é fechado, arborificado, acabou, do desejo nada mais passa; porque é sempre por rizoma que o desejo se move e produz. Toda vez que o desejo segue uma árvore acontecem as quedas internas que o fazem declinar e o conduzem à morte; mas o rizoma opera sobre o desejo por impulsões exteriores e produtivas.

O caminhar do cartógrafo é feito de passos que se sucedem sem distanciarem-se, como na ação de caminhar, onde um passo vem atrás do outro continuamente e enquanto houver desejo haverá caminhada. Portanto pode ser possível prever a participação dos membros do grupo, quando é traçado um plano que leve em conta o desejo de cada um.

Com a metodologia cartográfica foi possível refletir sobre todo trabalho desenvolvido a partir de uma iniciativa; como também perceber as dificuldades e facilidades ocasionadas pela diferença; além da oportunidade de pesquisar em grupo, de vivenciar um ensino significativo, despretensioso, que caminha por lugares desconhecidos, sem se prender a divisão de conteúdos por áreas e nem esperar que uma pessoa conduza o grupo. Portanto, foi uma experiência relevante, que vinculou interesses, desejos, afetos e compromissos, internos e externos. Algo que só pode ser experimentado com a cartografia por meio de encontros, em desdobramentos técnicos e expressivos que se complementaram e ativaram outros modos de vivenciar processos com a cerâmica e com a vida. 


\section{REFERÊNCIAS}

CANOTILHO, Maria Helena Pires César. Processos de cozedura em cerâmica. Portugal: [s.n.], 2003. Disponível em: <https://bibliotecadigital. ipb.pt/bitstream/10198/203/1/60\%20-\%20 Processos $\% 20 \mathrm{de} \% 20$ cozedura\%20em\%20cer\%C3\%A2mica.pdf>. Acesso em: 12 de julho, 2017.

CHAVARRIA, Joaquim. A cerâmica. Lisboa: Editorial Estampa, 2004.

CHITI, Jorge Fernández. Manual de Esmaltes Cerámicos: Tercera edición restructurada y ampliada. Tomo 1. Argentina: Condorhuasi, 1988.

DELEUZE, G. e GUATTARI, F. Mil Platôs: capitalismo e esquizofrenia 2, v.1. São Paulo: Ed. 34, 2011.

FIGUEIREDO, Sérgio. NUPEART - Núcleo Pedagógico de Educação e arte: 2000 - 2005. Revista NUPEART, Florianópolis: UDESC/CEART, v. 3, n. 3, p. 108-125, set. 2004/2005.

FONSECA da SILVA, M. ET at. Programa Nupeart: Sistematizando Ações de Ensino, Pesquisa e Extensão. Revista NUPEART, Florianópolis: UDESC/ CEART, v. 9, n. 3, p. 79-89, 2011.

GALLO, Silvio. Deleuze \& a Educação. Belo Horizonte: Autêntica, 2008.

KASTRUP, V.; PASSOS, E.; ESCÓSSIA, L. Pistas do método da cartografia: pesquisa-intervenção e produção de subjetividade. Porto Alegre: Editora Sulina, 2015.

KASTRUP, Vírginia. O funcionamento da atenção no trabalho do cartógrafo. In: PASSOS, E.; KASTRUP, V.; ESCÓSSIA, L. (Org.). Pistas do método da cartografia: pesquisa-intervenção e produção de subjetividade. Porto Alegre: Sulina, 2009. p. 32-51.

MUZZILLO, Ocléris. Cerâmica sem segredo. Curitiba: Autores Paranaenses, 2014.

PASSOS, E., BENEVIDES DE BARROS, R. A Cartografia como método de pesquisa-intervenção. In: PASSOS, E.; KASTRUP, V.; ESCÓSSIA, L. (Org.). Pistas do método da cartografia: pesquisa-intervenção e produção de subjetividade. Porto Alegre: Sulina, 2009. p. 17-31. 